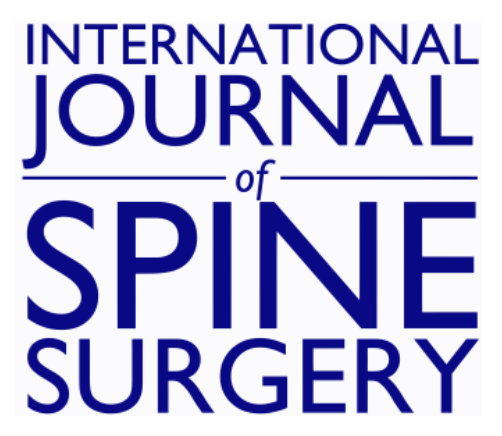

\title{
Surgical Management of Charcot Spinal Arthropathy in the Face of Possible Infection
}

Alexander Von Glinski, Sven Frieler, Christopher J. Elia, Darius Ansari, Clifford Pierre, Basem Ishak, Ronen Blecher, Bilal Qutteineh, Sarah Strot, Rod J. Oskouian and Jens R. Chapman

Int J Spine Surg 2021, 15 (4) 752-762

doi: https://doi.org/10.14444/8097

http://ijssurgery.com/content/15/4/752

This information is current as of April 26, 2023.

Email Alerts Receive free email-alerts when new articles cite this article. Sign up at: http://ijssurgery.com/alerts 


\title{
Surgical Management of Charcot Spinal Arthropathy in the Face of Possible Infection
}

\author{
ALEXANDER VON GLINSKI, MD, ${ }^{1,2,3,4}$ SVEN FRIELER, MD, ${ }^{1,2,3,4}$ CHRISTOPHER J. ELIA, DO, ${ }^{1,2,5}$ \\ DARIUS ANSARI, BS, ${ }^{1,2}$ CLIFFORD PIERRE, MD,${ }^{1,2}$ BASEM ISHAK, MD,${ }^{1,2,6}$ RONEN BLECHER, MD, ${ }^{1}$

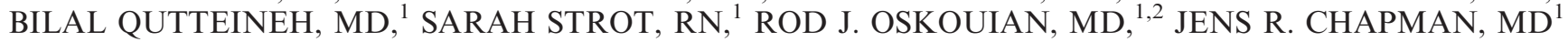 \\ ${ }^{1}$ Swedish Neuroscience Institute, Swedish Medical Center, Seattle, Washington, ${ }^{2}$ Seattle Science Foundation, Seattle, Washington, ${ }^{3}$ Department of Trauma \\ Surgery, BG University Hospital Bergmannsheil, Ruhr University Bochum, Bochum, Germany, ${ }^{4}$ Hansjörg Wyss Hip and Pelvic Center, Swedish Hospital, Seattle, \\ Washington, ${ }^{5}$ Department of Neurosurgery, Riverside University Health Systems, Moreno Valley, California, ${ }^{6}$ Department of Neurosurgery, Heidelberg University \\ Hospital, Heidelberg, Germany
}

\begin{abstract}
Background: The design is a retrospective cohort study. Charcot spinal arthropathy (CSA) is a rare and poorly understood progressive destructive spine condition that usually affects patients with preexisting spinal cord injury. The complexity of this condition, especially when additionally burdened by superimposed infection in the CSA zone, can potentially lead to suboptimal management such as protracted antibiotic therapy, predisposition to hardware failure, and pseudarthrosis. While in noninfected CSA primary stabilization is the major goal, staged surgical management has not been stratified based upon presence of a superinfected CSA. We compare clinical and radiological outcomes of surgical treatment in CSA patients with and without concurrent spinal infections.

Methods: Our single-institution database was reviewed for all patients diagnosed with CSA and surgically treated, who were subsequently divided into 2 cohorts: spinal arthropathy with superimposed infection and those without. Those were comparatively studied for complications and reoperation rate.

Results: Fifteen patients with CSA underwent surgical intervention; mean follow up of 15.3 months (range, 0-43). Eleven patients received stabilization with a quadruple-rod thoracolumbopelvic construct, while 4 patients with superinfected CSA underwent a staged procedure. Patients treated with a staged approach experienced fewer intraoperative complications $(0 \%$ versus $18 \%)$ and fewer revision surgeries $(25 \%$ versus $36 \%)$. Both cohorts had the same eventual healing.

Conclusions: Surgical management in CSA patients with primary emphasis on stability and modified surgical treatment based on presence of an active infection in the zone of neuropathic destruction will lead to similar eventual successful results with relatively few and manageable complications in this challenging patient population.

Level of Evidence: 4.

Clinical Relevance: The proposed treatment algorithm including the use of a quadruple-rod construct with lumbopelivic fixation and a staged approach in patients with superinfected CSA represents a reasonable option in the surgical treatment of CSA.

Lumbar Spine
\end{abstract}

Keywords: quadruple-rod construct, bone morphogenic protein (BMP), polymethylmethacrylate (PMMA), Hounsfield unit (HU)

\section{INTRODUCTION}

Charcot spinal arthropathy (CSA) is a relatively rare condition characterized by complex progressive destruction of the affected vertebral motion segments due to lack of protective proprioceptive afferent innervation, most often as a remote complication of spinal cord injury (SCI). ${ }^{1,2}$ It is believed that CSA results from the absence of supportive active muscular support secondary to nociceptive and/or proprioceptive impairment in the setting of SCI and is estimated to generally affect
1/220 SCI patients. ${ }^{3}$ Loss of the protective mechanisms that normally inhibit repetitive microtrauma to weightbearing articulations can set in motion an inflammatory process resulting in hypersclerosis of bone as well as exuberant periosteal and periarticular osteophyte formation accompanied by a mixture of progressive osteolysis, spinal deformity, instability, and potential for ascending neurological impairment. ${ }^{4}$ In the absence of an effective prevention program, timely recognition and monitoring assumes a vital role to avoid significant debilitating multisystem disease manifestations. Surgical indica- 
tions for CSA treatment include loss of postural trunk alignment, progressive destruction of the spinal column, and presence of recurrent infections in and emanating from the zone of neuropathic destruction. Goals of such surgery include permanent spine stabilization resulting in firm arthrodesis in a functionally suitable alignment after debridement of necrotic or inflamed tissue and control of any superimposed infection. ${ }^{5}$ The complexity of this condition, especially when additionally burdened by superimposed infection in the CSA zone, can potentially lead to suboptimal management such as unnecessary protracted antibiotic therapy or predisposition of the surgical patient to hardware failure and pseudarthrosis due to misunderstanding of the underlying disease. ${ }^{6}$ Surgical management has previously been detailed in expanded case series but, to our knowledge, has not been stratified based upon presence of an active infection in the neuropathic destruction zone. At our institution, we use a consistent posterior surgical approach for CSA patients requiring surgery emphasizing stabilization with a quadruple-rod construct with pelvic fixation after debridement of the neuropathic destruction zone followed by anterior column reconstruction with a cage and augmented bone grafting. In contrast, individuals with an identified active superimposed infection in the neuropathic destruction zone would routinely be managed in a staged procedure with debridement of infected and necrotic tissue and insertion of a temporary antibiotic laced polymethylmethacrylate (aPMMA) spacer into the defect zone and quadruple instrumentation before conversion to a definitive arthrodesis procedure after the infection had been resolved under the use of intravenous antibiotics administered over several weeks.

The purpose of our study was to compare clinical and radiographic outcomes of CSA patients treated with and without known infection in the neuropathic zone of destruction and to assess differences in clinical pathways between these 2 cohorts to provide guidance toward improved diagnostic and therapeutic decision making for these very challenging patients.

\section{METHODS}

Our prospectively collected spine surgery database was retrospectively reviewed after approval by our Institutional Review Board at Swedish Neuroscience Institute (IRB ID STUDY2019000337) for all patients with CSA between January 1st, 2006, and June 29th, 2019. A thorough structured chart and radiographic review was performed independently by 2 fellowship-trained spine surgeons to confirm the diagnosis of CSA with a further third party in the form of an independent neuroradiologist to gather clinical and radiographic data according to previously described key parameters. ${ }^{4-9}$ Data collected from each patient included age, gender, body mass index, presenting symptoms at the time of diagnosis, the presence of known concomitant infection, and the actual segment(s) affected by CSA. Preoperative computed tomography (CT) scans and, where available, magnetic resonance imaging scans were examined for radiographic signs of CSA, presence of osteomyelitis, and local bone density as determined by averaging the Hounsfield units (HU) of the vertebral bodies directly above and below the level of CSA. ${ }^{10,11}$ The underlying diagnosis (index condition) leading to CSA and the initially chosen treatment (index procedure), if any, were recorded. For patients having undergone a prior index procedure, we counted the number of levels fused during the index treatment, the grade and level of SCI caused by the index condition, and the time between the onset of the index condition and diagnosis of CSA.

Regarding surgical characteristics, we assessed for clinical presence of infection or superinfection of the involved Charcot joints, number and types of planned and unplanned procedures, intraoperative blood loss, as well as the amount and type of blood products transfused. In all patients, intraoperative microbiology cultures were obtained and assessed. Patients in whom infection was either suspected preoperatively or manifested intraoperatively, such as with presence of purulence, a multistaged surgery, as described in the succeeding section was performed. Postoperative complications (wound infection, instrumentation failure, pseudarthrosis, new Charcot joint formation, and medical complications) were recorded and analyzed separately for the 2 groups. CT scans were obtained to confirm bony arthrodesis by 1-year follow up and until fusion was confirmed in 6-month follow-up intervals. Radiographic iliac screw loosening was defined as $\geq 2 \mathrm{~mm}$ of periscrew lucency on follow-up radiographs or CT scans. ${ }^{12}$ Patient follow up was defined as the length of time from first surgical treatment of CSA to the most recent outpatient clinic visit. 

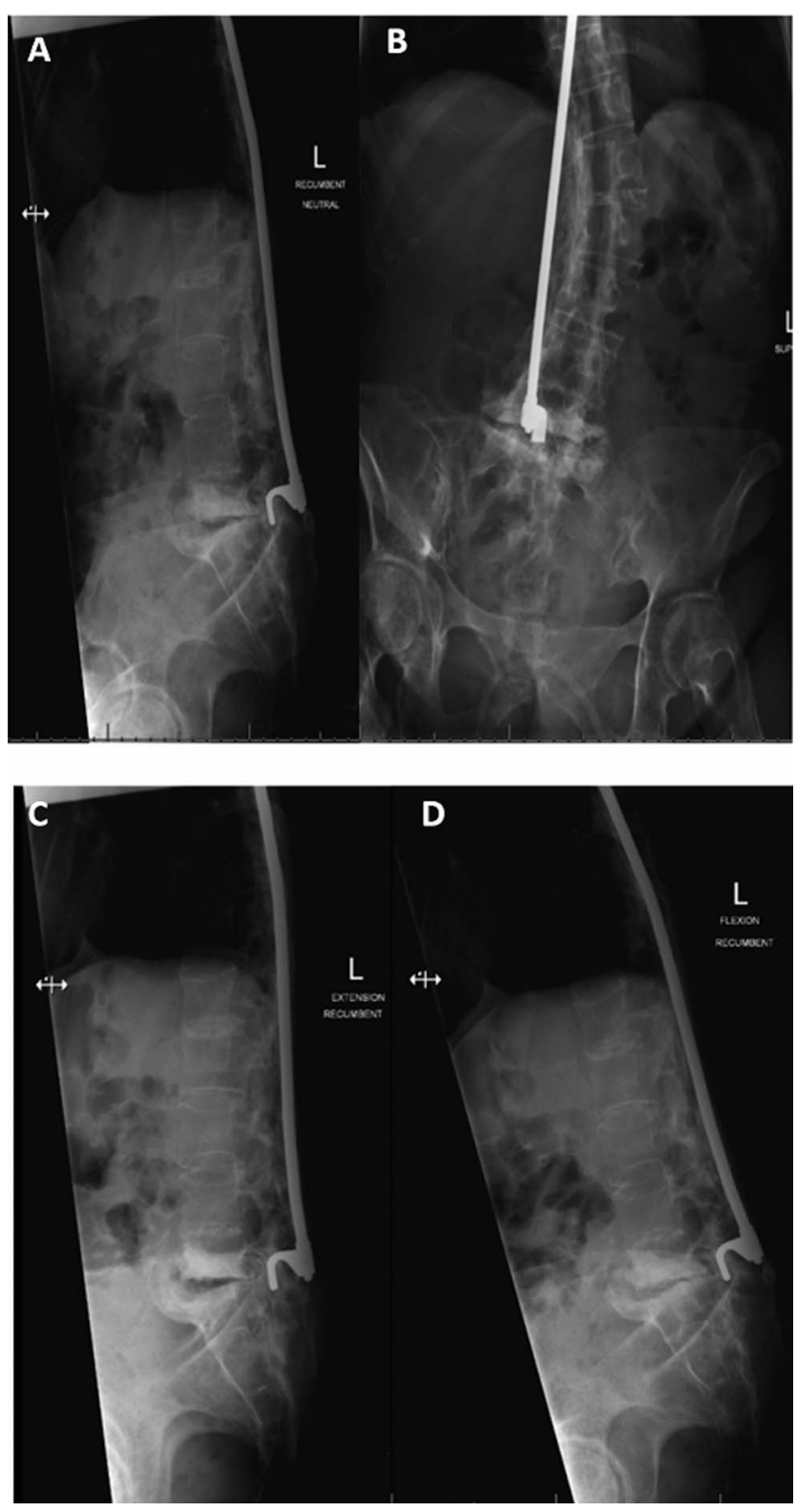

Figure 1. Patient 2 (71F): Midthoracic (T4) spinal cord injury, unstable L5-S1 junction. (A) (left top) and (B) (right top) Anterior/posterior and lateral, (C) (left bottom) extension, and (D) (right bottom) flexion views.

\section{Surgical Technique and Interdisciplinary Treatment Approach}

In the absence of contraindications, cell saver and tranexamic acid were used in all cases.

Posterior surgical exposure of the thoracolumbopelvic region was carried out, and previously placed hardware, if present in the area of surgical concern, was removed. The neuropathic zone of destruction was exposed from a posterolateral approach under preservation of the central neural tube and nerve roots. Intraoperative microbiology specimens and fresh frozen specimens of the reactive soft tissue area were gathered and analyzed. Debridement followed by pulsed lavage irrigation of the zone of neuropathic destruction was carried out up to the healthy spinal column end rostrally and caudally. In the presence of a visibly active infection, the debridement was followed by insertion of a structural aPMMA spacer as previously described. ${ }^{13}$ In the absence of an obvious purulent process, singlestage reconstruction of the anterior column was carried out with a large diameter titanium or polyetheretherketone cage and filled in its core, surroundings, and posterolaterally with a mixture of local graft, morselized allograft, and off-label bone morphogenic protein (BMP). Regardless of presence of an active infection of the CSA zone, posterior segmental stabilization was carried out with spanning rods and 2 outrigger rods assembled into a quadruple-rod construct, with additional rods (satellite rods) used individually depending on the location of the CSA. For pelvic fixation, we used a modified iliac screw entry point technique to maximize stability by avoiding side connectors and to allow for multiple iliac screws if necessary. ${ }^{13}$ For a second surgery in case of active infection in the CSA zone, we staged this procedure after the infection had received targeted intravenous antibiotics for 6-8 weeks with documented decrease of their inflammatory markers (C-reactive protein [CRP] and erythrocyte sedimentation rate) and elevation of their serum albumin to above $3.5 \mathrm{mg} /$ $\mathrm{dL}$. This second-stage surgery consisted of repeat tissue sampling for microbiological analysis, washout with copious amounts of pulsatile lavage, removal of all posterior instrumentation, and oversizing screw diameters by at least $1 \mathrm{~mm}$ with exchange of rods, removal of the aPMMA spacers, and placement of an interbody or corpectomy cage with allograft to promote arthrodesis as described for the primary surgery (Figure 1). A plastic surgeon routinely comanaged all patients with present or anticipated wound healing impairment. Further, all CSA patients received perioperative care by a multidisciplinary team including, in addition to other specialty surgeons, hospital medicine physicians, infectious disease specialists, rehabilitation medicine experts, and specialized physical and occupational therapists.

\section{RESULTS}

We identified 17 surgical patients with confirmed diagnoses of CSA treated between January 1st, 


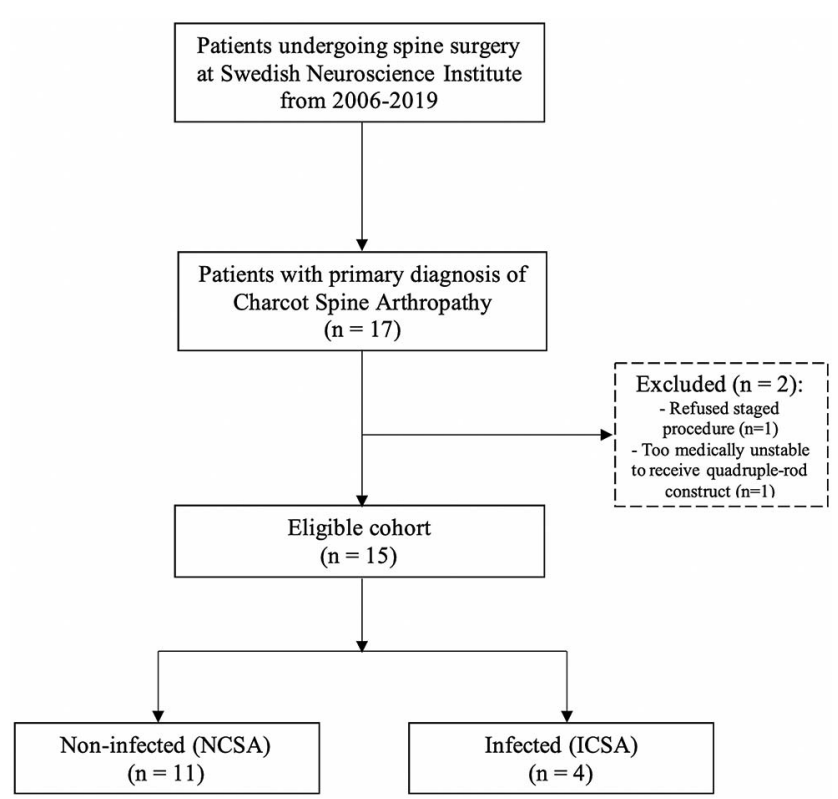

Figure 2. Identification and exclusion of study cohort.

2006, and June 29th, 2019 (Figure 2). Two patients were excluded from this evaluation: 1 patient with preoperatively known active infection of the CSA destruction zone refused instrumentation after debridement and aPMMA insertion, while another patient undergoing emergency treatment was deemed not medically stable to proceed with the quadruple-rod construct procedure due to acute sepsis. Due to their circumstances, both patients received minimum necessary care outside of our protocol and were therefore not part of this outcomes study.

Four patients (mean age $=61.25$ years) presented with a superinfected CSA (ICSA group), while 11 patients (mean age $=55.54$ years) presented with noninfected CSA (NCSA group). Positive intraoperative cultures and surgical findings consistent with infection were found in all ICSA. Five patients $(33.3 \%)$ were initially misdiagnosed with primary vertebral osteomyelitis, all of whom were treated nonsurgically with intravenous antibiotics before presentation at our facility. Two of those misdiagnosed patients turned out to have ICSA (Table 1; Figure 3).

All patients in the study cohort had developed CSA at the SCI level or below. Using the American Spinal Injury Association (ASIA) impairment scale, all patients were confirmed with an ASIA Grade A injury (Table 1$)$. In 14 patients $(93.3 \%)$, the index condition was traumatic SCI. One patient's index condition was nontraumatic in nature. Although the thoracic spine was the most common level of index SCI $(13 / 15,86.6 \%)$, the lumbar spine was the most common location for the development of CSA $(12 / 15,80 \%)$. While 1 patient underwent an index surgery in the ICSA group $(25 \%), 9(81.8 \%)$ patients underwent an index surgery in the NCSA group. Except for 1 case (pedicle screw fixation), all patients had been fused using a Harrington rod (Figure 4). In 5 patients, the CSA level was found to be 1 level distal to the caudal segment of the index fusion construct (Figure 5). The average time between the onset of the index condition and the diagnosis of CSA was 27.9 years (range, 13-48; standard deviation $(\mathrm{SD})=10.2$ years) with progressive pain, sitting intolerance, and fever comprising the most common presenting symptoms $(53.3 \%$, $26.7 \%$, and $26.7 \%$, respectively). ISCA average CRP was $91.5 \mathrm{mg} / \mathrm{dL}$ (range, 59.6-123) compared with $14.5 \mathrm{mg} / \mathrm{dL}$ (range, 0.6-30.2) in NCSA. With pathologic hypersclerotic bone at the CSA zone observed in $93.76 \%$ of the patients, the average HU was 113.0 (range, 62.5-159.12; $\mathrm{SD}=31.3$ ) at the vertebral bodies adjacent to the level of Charcot spine. All ICSA presented with gas formation in the disc space, while it was only present in 5 patients with NCSA (45\%)(Table 2).

The most common organism identified via intraoperative bone culture was Staphylococcus aureus (in 2/4). In 3 patients, a single organism was identified (2 with Staphylococcus aureus; 1 with methicillin-resistant coagulase-negative staphylococci), while 1 patient showed evidence of polymicrobial infection. Fungi and/or bacterial growth were also noted on preoperative urine, blood, and wound or ulcer cultures in all ICSA patients. The only type of preoperative culture that identified the same organism as the intraoperative culture was the sacral decubitus wound swab; the preoperative wound swabs matched intraoperative Enterococcus faecium in Case 8 and Staphylococcus aureus in Case 9 (Table 3).

The average duration of surgery in the NCSA group was 347.7 minutes (range, 284-501; SD = 64.6). These patients had a mean length of stay (LOS) of 10.31 days (range, 3.6-36; $\mathrm{SD}=9.35$ ), of which an average of 2.6 days was spent in the intensive care unit (ICU). In case of staged procedure (Figure 6), the duration of surgery was 327.7 minutes (range, 280-400; $\mathrm{SD}=62.8$ ) and 245 minutes (range, 200-231; $\mathrm{SD}=47.9$ ) for the second stage of the procedure. The total ICU stay was 2.9 
Table 1. Patient demographics.

\begin{tabular}{|c|c|c|c|c|c|c|c|c|}
\hline Case & Age & BMI & Cause of CSA & $\begin{array}{l}\text { Level of SCI } \\
\text { (ASIA Grade) }\end{array}$ & $\begin{array}{c}\text { Levels of } \\
\text { Initial Fusion }\end{array}$ & $\begin{array}{l}\text { No. CSA Levels } \\
\text { (Location) }\end{array}$ & $\begin{array}{c}\text { SCI-CSA } \\
\text { Interval (mo) }\end{array}$ & $\begin{array}{l}\text { Presenting } \\
\text { Symptoms }\end{array}$ \\
\hline 1 & 62 & 30.7 & Trauma & T8 (A) & T4-T10 (HR) & $\begin{array}{l}3 \text { (T10-T11, L3-L4, } \\
\text { L5-S1) }\end{array}$ & 39 & Pain \\
\hline 2 & 71 & 14.6 & $\begin{array}{l}\text { Trauma (hematoma } \\
\text { after cardiac } \\
\text { procedure) }\end{array}$ & $\mathrm{T} 4$ (A) & $\begin{array}{l}\text { T3-L5 (HR for } \\
\text { kyphoscoliosis) }\end{array}$ & $1(\mathrm{~L} 5-\mathrm{S} 1)$ & 19 & Incontinence \\
\hline 3 & 54 & 22.7 & Trauma & T4 (A) & T3-T5 (HR) & 1 (T11-T12) & 30 & Pain \\
\hline 4 & 58 & 23.5 & Trauma & T8 (A) & None & 1 (L2-L3) & 19 & Pain and instability \\
\hline 5 & 31 & 29.5 & Spinal cord infarct & T5 (A) & None & 1 (L2-L3) & 15 & Pain \\
\hline 6 & 58 & 17 & Trauma & T4 (A) & T3-L3 (HR) & 1 (L3-L4) & 16,5 & Nausea, malaise \\
\hline 7 & 52 & 32 & Trauma & T9 (A) & T5-L1 (HR) & 1 (L3-L4) & 20 & Pain \\
\hline 8 & 64 & 19.2 & Trauma & T9 (A) & T4-T9 (HR) & 1 (Т9-T10) & 20 & Weakness \\
\hline 9 & 59 & 24 & Trauma & C5 (A) & None & 1 (L4-L5) & 38 & Pain \\
\hline 10 & 61 & 17 & Trauma & T4 (A) & T3-T11 (HR) & $1(\mathrm{~L} 2-\mathrm{L} 3)$ & 32 & Weakness \\
\hline 11 & 64 & 30.9 & Trauma & T9 (A) & None & $1(\mathrm{~T} 10-\mathrm{T} 11)$ & 48 & Pain \\
\hline 12 & 58 & 16.5 & Trauma & T8 (A) & T4-L3 (H R) & 1 (L3-L4) & 28 & Pain \\
\hline 13 & 60 & 27.4 & Trauma & T8 (A) & None & 1 (L3-L4) & 30 & Fever and pain \\
\hline 14 & 56 & 33.28 & Trauma & $\mathrm{C} 4(\mathrm{~A})$ & None & 1 (L4-L5) & 39 & $\mathrm{AD}$ \\
\hline 15 & 48 & 46.9 & Trauma & T8 (A) & $\mathrm{T} 2-\mathrm{T} 1$ & $1(\mathrm{~T} 12-\mathrm{L} 1)$ & 13 & Pain and SI \\
\hline
\end{tabular}

Abbreviations: AD, autonomic dysreflexia; ASIA, American Spinal Injury Association; BMI, body mass index; CSA, Charcot spinal arthropathy; HR, Harrington rod; $\mathrm{ICH}$, intracranial hemorrhage; SCI, spinal cord injury; SCI-CSA interval, time elapsed between index injury and the onset of CSA symptoms; SI, sitting intolerance.

days (range, $2-3 ; \mathrm{SD}=0.6$ ) with a total LOS of 14.5 days (range, 11-18; $\mathrm{SD}=2.8$ ).

We encountered 2 intraoperative complications (both NCSA). One patient (Case 3) was found to have a hemothorax, which led to respiratory failure and readmission to the ICU, resolving after chest tube placement. One intraoperative durotomy repaired via dura plastic (Case 12; Table 4). We encountered 3 medical complications in the NCSA group (postoperative hypovolemic shock [Case 2] and postoperative tachycardia) requiring a blood transfusion.

The average clinical follow up was 15.3 months (range, $0-43 ; \mathrm{SD}=13.3$ ). In total, 5 patients underwent revision surgery $(33.3 \%)$ during the average clinical follow up, which was 15.3 months (range, $0-43 ; \mathrm{SD}=13.3$ ). In 1 case (NCSA group), we found radiological signs of bilateral loosening of the iliac screws 15 months after surgery without clinical complaints or pseudarthrosis. No additional CSA levels developed. A total of 3 mortalities occurred; 2 occurred more than a year after surgery, and none were deemed related to the surgical care by a peer panel.

\section{DISCUSSION}

Recognition and directed treatment of CSA remains insufficiently understood among the spine surgeon community. In 1980 , Wirth et $\mathrm{al}^{14}$ published a series of 23 cases with only 1 case related to spine trauma. In recent times, however, history of traumatic SCI has become the leading cause with
93.3\% prevalence in our cohort. ${ }^{6,15-18}$ Although the thoracic spine was the most common level of index SCI $(13 / 15,86.6 \%)$, the lumbar spine was the most common location for the development of CSA (12/ $15,80 \%)$. This may be attributable to the generally increased lumbar mobility which is subject to excessive torsional forces during the repetitive selftransfer activity in paraplegic patients. ${ }^{6}$ Additionally, long fusion constructs in paraplegic patients unavoidably place supraphysiological forces on adjacent caudal segments, contributing to the incidence of lumbar CSA. ${ }^{6,8}$ Harrington rods, which were the most common index procedure, provide less resistance to torsional stresses, which occur frequently in paraplegic patients during transfer activities, and may further increase the probability of CSA. ${ }^{19}$ Advancements in care and prolonged life expectancy in SCI patients contribute to the rising incidence of CSA, making the clinical and radiological awareness of CSA crucial. ${ }^{3,20}$

Elevated CRP values did appear to differentiate infected from noninfected cases, thus supporting the notion that CRP is a specific test for the detection of concomitant infection in the setting of CSA, especially when fever is a presenting symptom. Nevertheless, due to the delayed onset and rather nonspecific clinical signs, radiographic studies are mandatory tools in the workup and diagnosis of CSA. ${ }^{5,8,17}$ The correct identification of CSA has been notoriously challenging due to confusion with degenerative and/or infectious processes. The progressive osseous and ligamentous destruction may result in a radiological appearance that mimics 


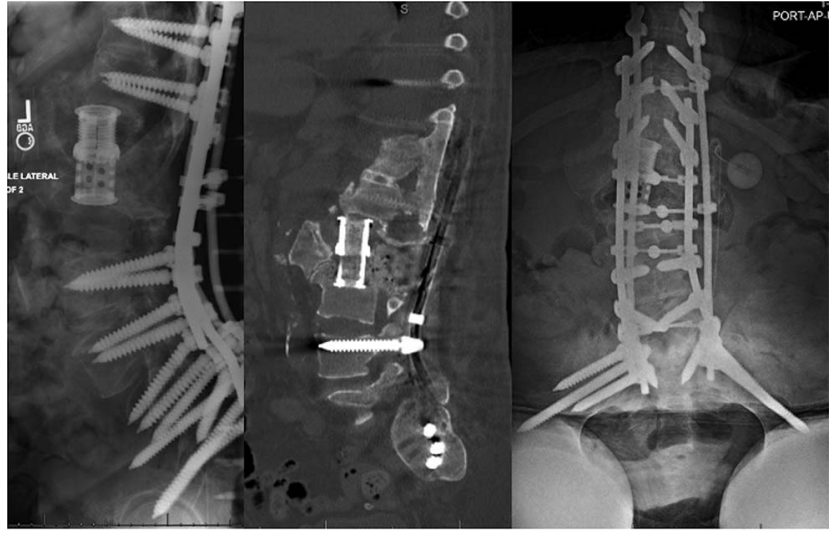

Figure 3. Patient 4: Second-stage surgery 21 days after polymethylmethacrylate strut insertion. One temporary rod broke caudally after transfer maneuver. Removal followed segmental instrumentation. Extensive aggressive debridement of spine and instrumentation tracks and completion L1-L3 vertebrectomies, pulsatile lavage, $9 \mathrm{~L}$, remove antibiotic spacers. Anterior lumbar interbody fusion with expandable cage, Stryker AVS, and bone morphogenic protein (BMP) and allograft. Posterior spinal instrumentation and fusion T8 to ilium with quadruple-rod fixation and multiple crosslinks and posterolateral fusion, and posterior lamina fusion L4-S1, with BMP allograft.

spinal infection. ${ }^{4,21}$ Especially in suspected infection, missed diagnosis of CSA carries with it a sequence of well-intended but usually futile attempts of imaging-directed aspiration attempts, prolonged periods of intravenous antibiotics, and occasional bracing as shown in our cohort, with 5 patients being misdiagnosed as osteomyelitis, of which 2 patients presented with superinfected CSA. ${ }^{5,8,17}$ While superimposed infection of CSA has been described as rare, ${ }^{8,21}$ we identified 4 such patients within our cohort. SCI patients are predisposed to infections such as pneumonia, skin or soft tissue infections, and urinary tract infections (UTIs), which might cause hematogenous infection. ${ }^{2-24}$ While hematogenous superinfection of CSA has been described, ${ }^{21}$ we found continuous infection secondary to a fistulous tract or an adjacent infected decubitus ulcer to be the most common way of infection in our cohort. ${ }^{5}$ Two patients had the same bacterial growth found on sacral decubitus ulcer as well as the deep tissue culture, suggesting possible infection via fistulous skin track. ${ }^{5}$ While $50 \%$ of the infected patients in our cohort had positive urine cultures, none of these cases had the same bacteria colonization intraoperatively. Furthermore, only 1 patient had positive blood cultures. The authors conclude that, although UTI is common in this patient population, it is not likely the source of superimposed infection as typically seen with spinal infections; rather, it is likely secondary to the

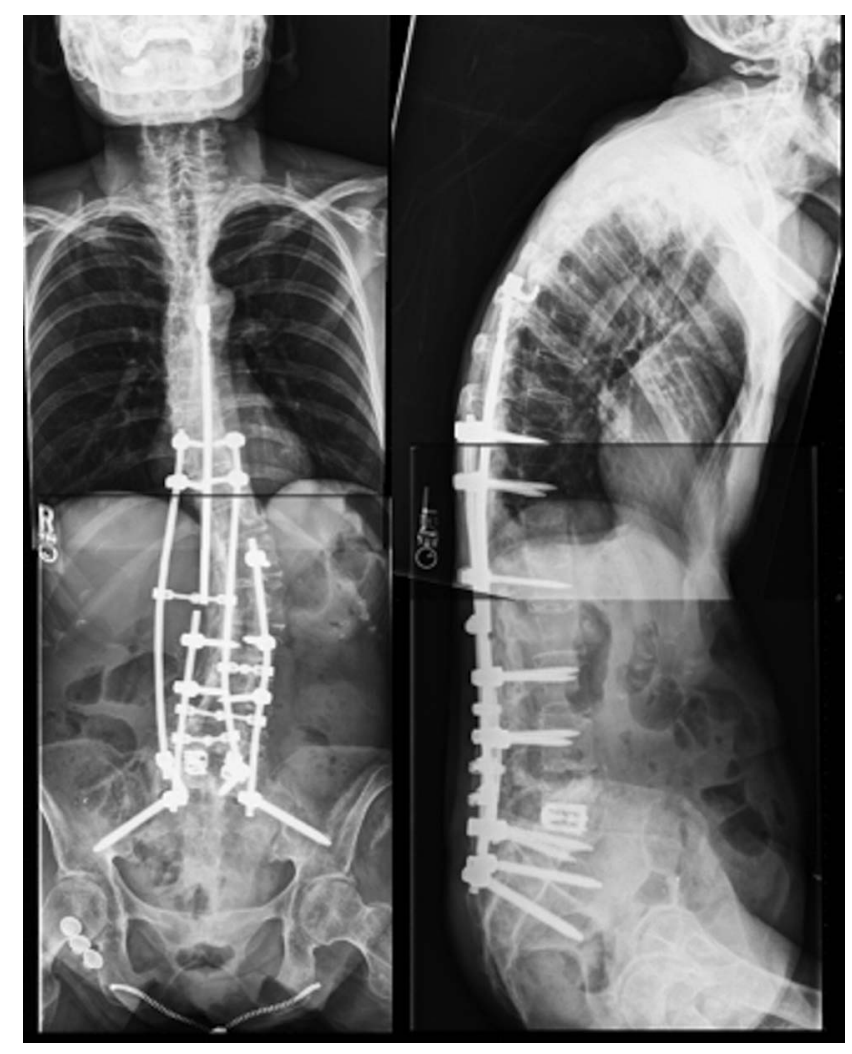

Figure 4. Patient 2: Partial removal caudal end of Harrington rod laminectomy, and epidural debridement, L5-S1. Posterior interbody fusion with bilateral expandable titanium cage with bone morphogenic protein (BMP) with local and allograft bone and posterior spinal instrumentation T10 to pelvis with quadruple-rod construct. L5-S1 fusion, posterolateral fusion and fusion to ilium using local bone and allograft BMP.

patient's comorbid conditions or an adjacent decubitus ulcer infection.

Surgical care of CSA has traditionally been associated with high complication rates, as reported with heterogenous techniques to achieve a stable

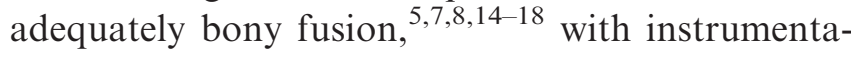
tion loosening and wound healing complications being 2 of the main concerns.

Aebli et $\mathrm{al}^{8}$ reported results of surgically managed CSA, citing a $28.6 \%$ instrumentation loosening rate and a $38 \%$ reoperation rate. Devlin et $\mathrm{al}^{25}$ reported 10 cases of CSA, of which 6 experienced perioperative complications while $4(40 \%)$ were directly instrumentation related (screw pullout, anterior graft dislodgement, rod breakage). This is the first study, to our knowledge, featuring a homogenous treatment algorithm proposed by Jacobs et $\mathrm{al}^{6}$ and recognizing the role of superinfection by the concept of a staged procedure in CSA with concomitant infection. ${ }^{5,8,9,14,21,26-28}$ Jacobs et $\mathrm{al}^{6}$ advocated to treat Charcot arthropathy of the lumbar spine with a lumbopelvic quadruple-rod construct. This miti- 
DSCI Level aCSA Level

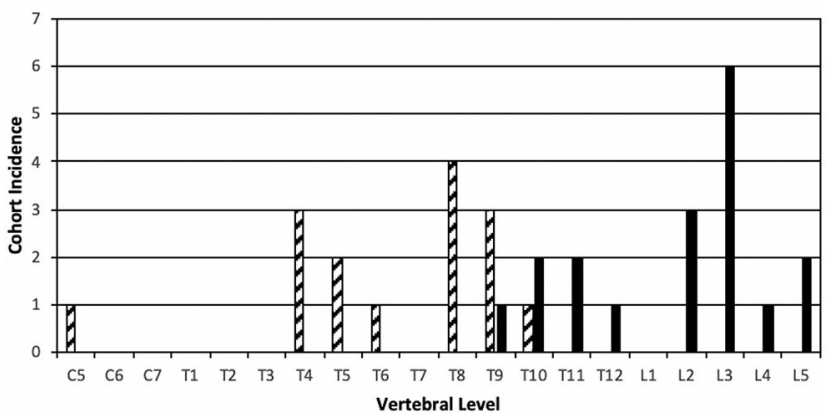

Figure 5. Distribution of spinal cord injury (SCI) and Charcot spinal arthropathy (CSA) incidence by vertebral level. Note CSA levels typically develop distal to level of $\mathrm{SCI}$.

gates flexion, extension, and axial rotation at L5-S1 and especially in paraplegic patients, who bear excessive lumbosacral loads during bed transfers and mobilization, and has been shown to decrease the instrumentation failure rate in short-term follow up. $^{29-31}$ In addition to biomechanical demands in this patient collective, Charcot patients are known to have an associated decrease in bone mineral density (BMD) with disease progression attributable to their comorbid conditions, especially SCI, resulting in accelerated BMD loss. ${ }^{7,32-37}$ Our study is the first, to our knowledge, to apply HU values to a cohort of patients with CSA, which has proven to be helpful in predicting BMD in patients undergoing instrumented fusion. ${ }^{38-40}$ As expected, our cohort had an average HU value of 113.0, which places them at high risk for instrumentation-related complications, as low HU $(<116.4)$ has been associated with cage subsidence ${ }^{41}$ and pedicle screw loosening in thoracolumbar fusions. ${ }^{42}$ While this

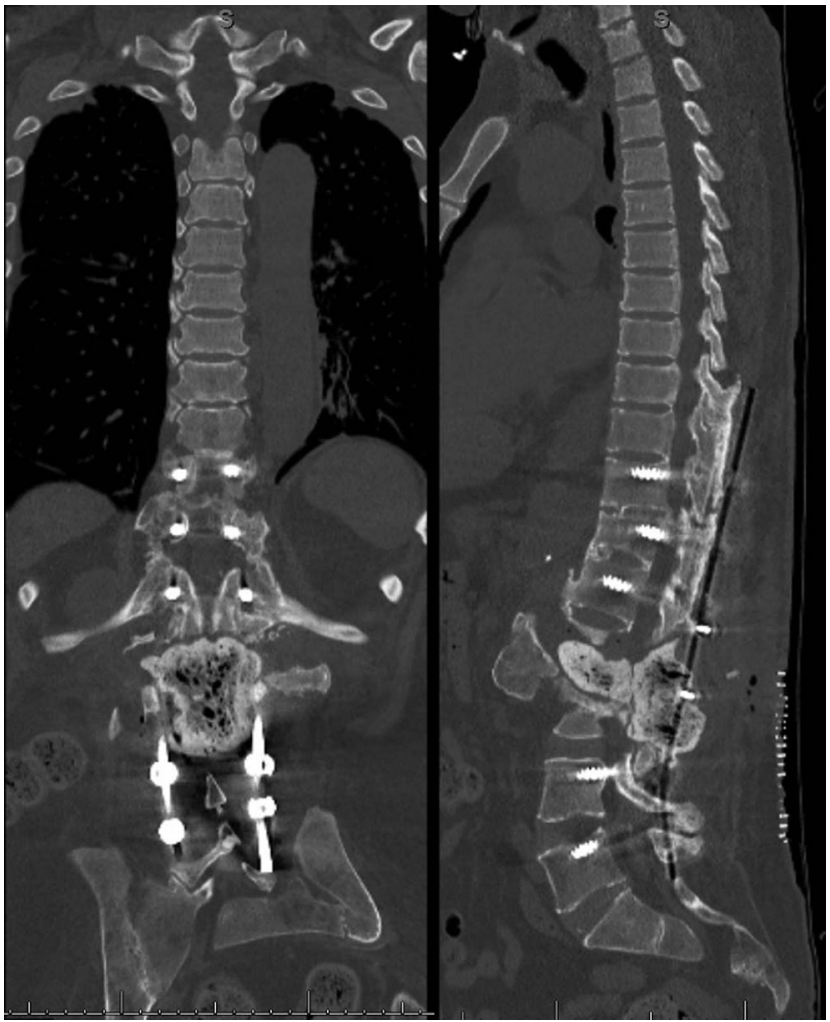

Figure 6. Patient 4: Extensive destructive Charcot arthropathy of L2 and L3 vertebral bodies and large paravertebral abscess. Wide decompressive laminectomies L1-L3, partial vertebrectomies L2 and L3, resection of abscess capsule, open reduction and internal fixation T11-L5, insertion polymethylmethacrylate strut graft $(2 \mathrm{~g}$ of Simplex nontobramycin cement and $4 \mathrm{~g}$ vancomycin), 2 crosslinks.

finding underlines the biomechanical and biological need for lumbopelvic fixation, the functional impact of decreased lumbar spine mobility after instrumentation and fusion on daily tasks such as performing transfers, bladder self-catheterization, perineal hygiene, and stoma care where present cannot be

Table 2. Radiologic findings.

\begin{tabular}{|c|c|c|c|c|c|c|c|c|}
\hline Case & $\begin{array}{c}\text { Endplate } \\
\text { Involvement }\end{array}$ & $\begin{array}{l}\text { Gas in the } \\
\text { Disc Space }\end{array}$ & $\begin{array}{c}\text { Facet Joint } \\
\text { Fragmentation }\end{array}$ & Distention & $\begin{array}{c}\text { Increased } \\
\text { Density }\end{array}$ & Dislocation & HU & $\begin{array}{c}\text { Clinically Mistaken } \\
\text { for Vertebral } \\
\text { Osteomyelitis } \\
\end{array}$ \\
\hline 1 & & $\checkmark$ & $\checkmark$ & $\checkmark$ & $\checkmark$ & & 65.2 & \\
\hline 2 & $\checkmark$ & $\checkmark$ & $\checkmark$ & $\checkmark$ & $\checkmark$ & & 62.5 & \\
\hline 3 & $\checkmark$ & & $\checkmark$ & $\checkmark$ & $\checkmark$ & & 95.1 & $\checkmark$ \\
\hline 4 & $\checkmark$ & & $\checkmark$ & $\checkmark$ & $\checkmark$ & $\checkmark$ & 103.9 & $\checkmark$ \\
\hline 5 & $\checkmark$ & & $\checkmark$ & $\checkmark$ & $\checkmark$ & & 159.1 & $\checkmark$ \\
\hline 6 & $\checkmark$ & & & & $\checkmark$ & & 127.9 & $\checkmark$ \\
\hline 7 & $\checkmark$ & & & $\checkmark$ & $\checkmark$ & & 169 & \\
\hline 8 & $\checkmark$ & & $\checkmark$ & $\checkmark$ & $\checkmark$ & & 123 & \\
\hline 9 & $\checkmark$ & & $\checkmark$ & $\checkmark$ & $\checkmark$ & & 110.5 & $\checkmark$ \\
\hline 10 & $\checkmark$ & & $\checkmark$ & $\checkmark$ & $\checkmark$ & $\checkmark$ & 85.4 & \\
\hline 11 & $\checkmark$ & $\checkmark$ & & & $\checkmark$ & & 92.1 & \\
\hline 12 & $\checkmark$ & $\checkmark$ & $\checkmark$ & $\checkmark$ & $\checkmark$ & $\checkmark$ & 150.7 & \\
\hline 13 & $\checkmark$ & & & & $\checkmark$ & & 125.5 & \\
\hline 14 & $\checkmark$ & $\checkmark$ & $\checkmark$ & $\checkmark$ & $\checkmark$ & $\checkmark$ & 105 & \\
\hline 15 & $\checkmark$ & $\checkmark$ & $\checkmark$ & & $\checkmark$ & & 120 & \\
\hline
\end{tabular}

Abbreviation: HU, Hounsfield unit. 
Table 3. Infection characteristics.

\begin{tabular}{|c|c|c|c|c|c|c|c|c|}
\hline Case & $\begin{array}{l}\text { Preoperative } \\
\text { Urine Culture }\end{array}$ & $\begin{array}{l}\text { Preoperative Wound } \\
\text { or Ulcer Swab }\end{array}$ & $\begin{array}{l}\text { Intraoperative } \\
\text { Culture }\end{array}$ & Blood Culture & Treatment & Fever & $\begin{array}{l}\mathrm{CRP}, \\
\mathrm{mg} / \mathrm{dL}\end{array}$ & $\begin{array}{l}\mathrm{WBC} \times 10^{9} \\
\text { cells } / \mathrm{L}\end{array}$ \\
\hline 4 & Candida parapsilosis & $\mathrm{NC}$ & Staphylococcus aureus & $(-)$ & $\begin{array}{l}\text { Vancomycin (spacer), } \\
\text { Ampicillin/Sulbactam }\end{array}$ & Yes & 123 & 22.4 \\
\hline 8 & $\mathrm{NC}$ & $\begin{array}{l}\text { Candida parapsilosis, } \\
\text { Vancomycin-resistant } \\
\text { Enterococcus faecium }\end{array}$ & $\begin{array}{l}\text { Vancomycin-resistant } \\
\text { Enterococcus faecium, } \\
\text { Pseudomonas aeruginosa }\end{array}$ & $\begin{array}{l}\text { Citrobacter } \\
\text { freundii }\end{array}$ & $\begin{array}{l}\text { Ceftazidime, } \\
\text { Metronidazole, } \\
\text { Tigecycline, Linezolid }\end{array}$ & Yes & 111.4 & 17.2 \\
\hline 11 & Enterococcus spp. & $\mathrm{NC}$ & MR-CoNS & $(-)$ & $\begin{array}{l}\text { Vancomycin (IV), } \\
\text { Cefepime }\end{array}$ & No & 59.6 & 5.6 \\
\hline 9 & $\mathrm{NC}$ & Staphylococcus aureus & Staphylococcus aureus & $(-)$ & Rifampin, Cefazolin & Yes & 92 & 9.6 \\
\hline
\end{tabular}

Abbreviations: (-), negative culture; CRP, C-reactive protein; IV, intravenous; MR-CoNS, methicillin-resistant coagulase-negative staphylococci; $\mathrm{NC}=$ not collected; WBC, white blood cell.

neglected and must be discussed beforehand with the patient. ${ }^{8}$

While the largest existing case series have not reported the incidence of superimposed infection in CSA, we found an incidence of $26.7 \%$ in our cohort. ${ }^{6,8}$ Their therapeutic implications are less than clear, and a further delay in eventual treatment is common. ${ }^{8,21}$ Further, the safety and timing of surgical CSA care in the setting of a documented ongoing infection has previously not been described. In addition to instrumentation failure, deep wound infections are commonly encountered in the treatment of CSA and cause revision rates between $14 \%$ and $17 \%$, some of which may be attributable to superimposed infection. ${ }^{6,8}$ The high propensity for repeat infections, as seen in previously published studies, ${ }^{6,43}$ may be attributable to impaired immunity secondary to chronic illness as well as biofilm formation on permanent catheters or metal implants. ${ }^{44}$ As shown in our study, S. aureus is the most frequently isolated bacteria in patients with infected CSA; its capacity to form biofilms decreases the efficacy of antimicrobial agents and leads to chronic infections and wound healing complications. $^{45,46}$ The concept of an aPMMA spacer has been developed and established for treating periprosthetic joint infections and is considered off-label use in the setting of spinal infection. ${ }^{47,48}$ While there is still a lack of evidence in spine infections compared with periprosthetic joint infections, ${ }^{49-51}$ the first case series point out potential benefits in spinal osteomyelitis. ${ }^{48,52}$ The proposed 2-staged approach of placing a temporary aPMMA spacer into the anterior column dead space prevents seroma or hematoma formation while providing anterior column stabilization and high local concentrations of antibiotic with no known systemic toxicity. ${ }^{44,53}$ Moreover, it allows determination of antibiotic sensitivity and appropriate adjustment of antibiotic therapy, which remains the cornerstone in the treatment of osteomyelitis and is favorably reflected in the outcomes in our patients. ${ }^{53}$ With respect to the concern of how to proceed in the presence of an actual infection in the CSA zone, we found our intraoperative decision making with conversion to a 2-staged approach using aPMMA spacers in our limited series to be a safe and effective approach and not associated with any reinfections. ${ }^{47,48}$

Table 4. Revision surgery.

\begin{tabular}{|c|c|c|c|c|c|}
\hline Case & Group & Initial Surgery & Cause of Revision & Readmission & Procedure or Revision Surgery \\
\hline 3 & NCSA & T3-ilium FRC & Misplaced T8 pedicle screw & $\mathrm{N} / \mathrm{A}$ & Replacement of left T8 pedicle screw \\
\hline 4 & ICSA & $\begin{array}{l}\text { Staged PMMA } \\
\quad+\text { T11-ilium FRC }\end{array}$ & $\begin{array}{l}\text { Wound dehiscence or necrosis } \\
\text { thoracolumbar junction } \\
\text { (no infection) }\end{array}$ & $14 \mathrm{~d}$ after initial surgery & $\begin{array}{l}\text { VAC therapy, secondary wound closure } \\
\text { with plastic surgeon (wound } \\
\text { reconstruction with right and left } \\
\text { latissimus dorsi) }\end{array}$ \\
\hline 7 & NCSA & T2-ilium & $\begin{array}{l}\text { Wound dehiscence or necrosis } \\
\text { over LPF } \\
\text { (no infection) }\end{array}$ & $1 \mathrm{mo}$ after initial surgery & $\begin{array}{l}\text { Debridement, wound closure with } \\
\text { plastic surgeon using latissimus } \\
\text { dorsi and gluteus maximus flaps }\end{array}$ \\
\hline 12 & NCSA & T0-ilium FRC & $\begin{array}{l}\text { LPF instrumentation pullout } \\
\text { (L3-L4 CSA level) }\end{array}$ & 6 mo after initial surgery & Redirected iliac screws \\
\hline 15 & NCSA & T10-ilium FRC & Wound dehiscence (no infection) & $\mathrm{N} / \mathrm{A}$ & $\begin{array}{l}\text { VAC, wound reconstruction with } \\
\text { plastic surgeon using latissimus } \\
\text { dorsi and trapezius flap }\end{array}$ \\
\hline
\end{tabular}

Abbreviations: CSA, Charcot spinal arthropathy; FRC, four-rod construct; ICSA, infected CSA; LPF, lumbopelvic fixation; N/A, not applicable; NCSA, noninfected CSA; PMMA, polymethylmethacrylate; VAC, vacuum-assisted closure, 


\section{Limitations}

The main limitations of our study pertain to our limited number of patients assessed through a retrospective study design. Further, our mean follow-up time was 16.79 months, which is less than the 22 months reported by Jacobs et al. ${ }^{6}$ As they and other authors have reported, $50 \%$ of their instrumentation failures presented within a year from surgery, which was within our mean follow up. ${ }^{6,8,15}$ Due to the very large geographical drawing area of our patients, longer term follow up, even using remote radiographs and Internet-based telemedicine, was a difficult obstacle to overcome. However, if we examine instrumented patients with at least 1 year follow up, we observe an instrumentation failure rate of only $1 / 8(12.5 \%)$. Another limitation present is the lack of a control group documenting the outcome of nonoperative treatment of presumed osteodiscitis or osteomyelitis in a possible Charcot patient. As surgical management has become increasingly the treatment of choice for progressive destructive CSA, analysis of conservative treatment outcomes is bound to be a frustrating undertaking due to low patient numbers and very long multifactorial observation windows needed.

\section{CONCLUSIONS}

Treatment of CSA requires complex surgical decision making, given the patients' poor bone quality and high propensity for failure after surgery. Based on our treatment algorithm for CSA patients, we highly recommend aggressive management with debridement of necrotic or infected tissue, use of BMP (if not contraindicated), and the use of a quadruple-rod construct with lumbopelivic fixation to provide maximum fixation to prevent instrumentation failure or pseudarthrosis. Furthermore, we believe that a staged approach in patients with superinfected CSA is reasonable.

\section{REFERENCES}

1. Brown CW, Jones B, Donaldson DH, et al. Neuropathic (Charcot) arthropathy of the spine after traumatic spinal paraplegia. Spine (Phila Pa 1976). 1992;17(6 Suppl):S103S108.

2. Charcot JM. Sur quelques arthropathies qui paraissent de'pendre d'une lésion du cerveau ou de la moelle épinière. Arch Phys Norm Pathol. 1868;1(1):161-178.

3. Singh A, Tetreault L, Kalsi-Ryan S, et al. Global prevalence and incidence of traumatic spinal cord injury. Clin Epidemiol. 2014;6:309-331.

4. Ledbetter LN, Salzman KL, Sanders RK, et al. Spinal neuroarthropathy: pathophysiology, clinical and imaging features, and differential diagnosis. Radiographics. 2016;36(3):783799.

5. Morita M, Miyauchi A, Okuda S, et al. Charcot spinal disease after spinal cord injury. $J$ Neurosurg Spine. 2008;9(5):419-426.

6. Jacobs WB, Bransford RJ, Bellabarba C, et al. Surgical management of Charcot spinal arthropathy: a single-center retrospective series highlighting the evolution of management. $J$ Neurosurg Spine. 2012;17(5):422-431.

7. El Oraby HA, Abdelsalam MM, Eid YM, et al. Bone mineral density in type 2 diabetes patients with Charcot arthropathy. Curr Diabetes Rev. 2018;15(5):395-401.

8. Aebli N, Pötzel T, Krebs J. Characteristics and surgical management of neuropathic (Charcot) spinal arthropathy after spinal cord injury. Spine J. 2014;14(6):884-891.

9. Mohit AA, Mirza S, James J, et al. Charcot arthropathy in relation to autonomic dysreflexia in spinal cord injury: case report and review of the literature. $J$ Neurosurg Spine. 2005;2(4):476-480.

10. Schreiber JJ, Anderson PA, Rosas HG, et al. Hounsfield units for assessing bone mineral density and strength: a tool for osteoporosis management. J Bone Joint Surg Am. 2011;93(11):1057-1063.

11. Schreiber JJ, Anderson PA, Hsu WK. Use of computed tomography for assessing bone mineral density. Neurosurg Focus. 2014;37(1):E4. doi:10.3171/2014.5.FOCUS1483

12. Nguyen JH, Buell TJ, Wang TR, et al. Low rates of complications after spinopelvic fixation with iliac screws in 260 adult patients with a minimum 2-year follow-up [published online ahead of print February 1, 2019]. J Neurosurg Spine. doi: 10.3171/2018.9.SPINE18239

13. von Glinski A, Yilmaz E, Ishak B, et al. Neurovascular relations in modified iliac screws and the traditional iliac screw: An anatomical study. World Neurosurg. 2020134:e93-e97. doi: 10.1016/j.wneu.2019.09.090

14. Wirth CR, Jacobs RL, Rolander SD. Neuropathic spinal arthropathy. A review of the Charcot spine. Spine (Phila $\mathrm{Pa}$ 1976). 1980;5(6):558-567.

15. Crim JR, Bassett LW, Gold RH et al. Spinal neuroarthropathy after traumatic paraplegia. AJNR Am J Neuroradiol. 1988;9(2):359-362.

16. Gupta R. A short history of neuropathic arthropathy. Clin Orthop Relat Res. 1993;(296):43-49.

17. Barrey C, Massourides H, Cotton F, et al. Charcot spine: two new case reports and a systematic review of 109 clinical cases from the literature. Ann Phys Rehabil Med. 2010;53(3):200-220.

18. Harrison MJ, Sacher M, Rosenblum BR, et al. Spinal Charcot arthropathy. Neurosurgery. 1991;28(2):273-277.

19. Riebel GD, Yoo JU, Fredrickson BE, et al. Review of Harrington rod treatment of spinal trauma. Spine (Phila Pa 1976). 1993;18(4):479-491.

20. Collaborators GDaIIaP. Global, regional, and national incidence, prevalence, and years lived with disability for 328 diseases and injuries for 195 countries, 1990-2016: a systematic analysis for the Global Burden of Disease Study 2016. Lancet. 2017;390(10100):1211-1259.

21. Karthik Yelamarthy PK, Rustagi T, Mahajan R, et al. Infected Charcot spine arthropathy. Spinal Cord Ser Cases. 2018;8;4:73. doi:10.1038/s41394-018-0111-6

22. Garcia-Arguello LY, O'Horo JC, Farrell A, et al. 
Infections in the spinal cord-injured population: a systematic review. Spinal Cord. 2017;55(6):526-534.

23. Cardenas DD, Moore KN, Dannels-McClure A, et al. Intermittent catheterization with a hydrophilic-coated catheter delays urinary tract infections in acute spinal cord injury: a prospective, randomized, multicenter trial. $P M R$. 2011;3(5):408-417.

24. Bossa L, Kline K, McDougald D, et al. Urinary catheterassociated microbiota change in accordance with treatment and infection status. PLoS One. 2017;12(6): e0177633. doi:10.1371/ journal.pone.0177633

25. Devlin VJ, Ogilvie JW, Transfeldt EE, et al. Surgical treatment of neuropathic spinal arthropathy. J Spinal Disord. 1991;4(3):319-328.

26. Haus BM, Hsu AR, Yim ES, et al. Long-term follow-up of the surgical management of neuropathic arthropathy of the spine. Spine J. Jun 2010;10(6):e6-e16.

27. Selmi F, Frankel HL, Kumaraguru AP, et al. Charcot joint of the spine, a cause of autonomic dysreflexia in spinal cord injured patients. Spinal Cord. 2002;40(9):481-483.

28. Standaert C, Cardenas DD, Anderson P. Charcot spine as a late complication of traumatic spinal cord injury. Arch Phys Med Rehabil. 1997;78(2):221-225.

29. Shen FH, Qureshi R, Tyger R, et al. Use of the "dual construct" for the management of complex spinal reconstructions. Spine J. 2018;18(3):482-490.

30. Shen FH, Harper M, Foster WC, et al. A novel "fourrod technique" for lumbo-pelvic reconstruction: theory and technical considerations. Spine (Phila Pa 1976). 2006;31(12):1395-1401.

31. Suda Y, Shioda M, Kohno H, et al. Surgical treatment of Charcot spine. J Spinal Disord Tech. 2007;20(1):85-88.

32. Petrova NL, Foster AV, Edmonds ME. Calcaneal bone mineral density in patients with Charcot neuropathic osteoarthropathy: differences between Type 1 and Type 2 diabetes. Diabet Med. 2005;22(6):756-761.

33. Young MJ, Marshall A, Adams JE, et al. Osteopenia, neurological dysfunction, and the development of Charcot neuroarthropathy. Diabetes Care. 1995;18(1):34-38.

34. Jirkovská A, Kasalický P, Boucek P, et al. Calcaneal ultrasonometry in patients with Charcot osteoarthropathy and its relationship with densitometry in the lumbar spine and femoral neck and with markers of bone turnover. Diabet Med. 2001;18(6):495-500.

35. Szollar SM, Martin EM, Sartoris DJ, et al. Bone mineral density and indexes of bone metabolism in spinal cord injury. Am J Phys Med Rehabil. 1998;77(1):28-35.

36. Morse LR, Battaglino RA, Stolzmann KL, et al. Osteoporotic fractures and hospitalization risk in chronic spinal cord injury. Osteoporos Int. 2009;20(3):385-392.

37. Garland DE, Adkins RH, Kushwaha V, et al. Risk factors for osteoporosis at the knee in the spinal cord injury population. J Spinal Cord Med. 2004;27(3):202-206.

38. Choi MK, Kim SM, Lim JK. Diagnostic efficacy of Hounsfield units in spine CT for the assessment of real bone mineral density of degenerative spine: correlation study between T-scores determined by DEXA scan and Hounsfield units from CT. Acta Neurochir (Wien). 2016;158(7):1421-1427.

39. Schreiber JJ, Hughes AP, Taher F, et al. An association can be found between Hounsfield units and success of lumbar spine fusion. HSS J. 2014;10(1):25-29.

40. von Glinski A, Elia C, Ansari D, et al. Complications and mortality in octogenarians undergoing lumbopelvic fixation. World Neurosurg. 2020;134:e272-e276. doi:10.1016/j. wneu.2019.10.040

41. Mi J, Li K, Zhao X, et al. Vertebral body Hounsfield units are associated with cage subsidence after transforaminal lumbar interbody fusion with unilateral pedicle screw fixation. Clin Spine Surg. 2017;30(8):E1130-E1136.

42. Bredow J, Boese CK, Werner CM, et al. Predictive validity of preoperative CT scans and the risk of pedicle screw loosening in spinal surgery. Arch Orthop Trauma Surg. 2016;136(8):1063-1067.

43. Suresh MK, Biswas R, Biswas L. An update on recent developments in the prevention and treatment of Staphylococcus aureus biofilms. Int J Med Microbiol. 2019;309(1):1-12.

44. Stewart PS. Mechanisms of antibiotic resistance in bacterial biofilms. Int J Med Microbiol. 2002;292(2):107-113.

45. Donlan RM, Costerton JW. Biofilms: survival mechanisms of clinically relevant microorganisms. Clin Microbiol Rev. 2002;15(2):167-193.

46. Patel R. Biofilms and antimicrobial resistance. Clin Orthop Relat Res. 2005;X(437):41-47. doi:10.1097/01.blo. 0000175714.68624 .74

47. Anagnostakos K, Meyer C. Antibiotic elution from hip and knee acrylic bone cement spacers: a systematic review. Biomed Res Int. 2017;2017:4657874. doi:10.1155/2017/4657874

48. Osmon DR, Berbari EF, Berendt AR, et al. Diagnosis and management of prosthetic joint infection: clinical practice guidelines by the Infectious Diseases Society of America. Clin Infect Dis. 2013;56(1):e1-e25.

49. Klingler JH, Kruger MT, Sircar R, et al. PEEK cages versus PMMA spacers in anterior cervical discectomy: comparison of fusion, subsidence, sagittal alignment, and clinical outcome with a minimum 1-year follow-up. Sci World J. 2014;2014:398396. doi:10.1155/2014/398396

50. Garfin SR, Yuan HA, Reiley MA. New technologies in spine: kyphoplasty and vertebroplasty for the treatment of painful osteoporotic compression fractures. Spine (Phila Pa 1976). 2001;26(14):1511-1515.

51. Varga PP, Jakab G, Bors IB, et al. Experiences with PMMA cement as a stand-alone intervertebral spacer: percutaneous cement discoplasty in the case of vacuum phenomenon within lumbar intervertebral discs. Orthopade. 2015;44(Suppl 1):S1-S7.

52. Ramey WL, von Glinski A, Jack A, et al. Antibioticimpregnated polymethylmethacrylate strut graft as a treatment of spinal osteomyelitis: case series and description of novel technique. J Neurosurg Spine. 2020:1-6. doi:10.3171/2020.3. SPINE191313

53. Cierny G 3rd, DiPasquale D. Treatment of chronic infection. J Am Acad Orthop Surg. 2006;14(10 Spec No.):S105S110.

Disclosures and COI: The authors report no conflict of interest or financial support concerning the materials or methods used in this study or the findings specified in this paper. No relevant financial activities outside the submitted work. The manuscript submitted does not contain information about medical device(s)/drug(s). We certify that all applicable institutional and governmental regulations 
concerning the ethical use of clinical data were followed during this research. This study (IRB ID STUDY No. 2019000337) was approved by the Institutional Review Board at Swedish Neuroscience Institute. The data that support the findings of this study are available on request from the corresponding author (AvG). The data are not publicly available due to privacy restrictions. AvG was responsible for the study protocol, conducting the search, screening potentially eligible patients, extracting and analyzing data, interpreting results, and writing the paper. SF contributed to data evaluation, conception of the manuscript and writing the draft, and reviewed the manuscript. CE was responsible for reviewing and screening potentially eligible patients. He contributed to writing the report, extracting and analyzing data, interpreting results. DA contributed to the design of the review protocol, writing the study, and screening possible patients. CP contributed to data extraction and provided feedback on the study. BI contributed to data extraction and interpretations as well as drafting the manuscript. RB helped reviewing the script and reviewing all included patients regarding the diagnosis of Charcot spinal arthropathy (CSA). BQ helped screening patients, drafting the manuscript, and analyzing the radiographs. SH helped to identify all possible patients with CSA as well as drafting and revising the manuscript. RO helped with developing the study, drafting the manuscript, and revised it. Further he supervised the project. JC supervised the project, reviewed all included patients, and revised the manuscript.

Corresponding Author: Alexander von Glinski, MD, Swedish Neuroscience Institute, 550 17th Avenue, Suite 500, Seattle, WA 98122. Phone: (206) 475-9514; Fax: (206) 732-6599; Email: alexandervonglinski@icloud.com.

Published 19 August 2021

This manuscript is generously published free of charge by ISASS, the International Society for the Advancement of Spine Surgery. Copyright (C) 2021 ISASS. To see more or order reprints or permissions, see http://ijssurgery.com. 